\title{
Research on Application of Translation in English Teaching
}

\author{
Yang Jiaoyan \\ No. 105, 30 th Teacher's Dormitory, Sichuan Agricultural University, Wenjiang District, Chengdu, \\ Sichuan Province, China
}

Email:937653817@qq.com

\section{Key Words: Translation, Foreign Language, Necessity, Application}

Abstract. Translation has long been applied to English Teaching in China with its prosperity, decline and revival. It is of great assistance to Chinese English learners given the insufficient language environment. The paper focuses on the application of translation in English Teaching.

\section{Introduction}

There are close correlations between translation and English teaching: translation promotes the mastery of English and serves to facilitate the instruction of grammar and vocabulary. Translation, as an approach to English teaching, has prospered, withered and again thrived with the reform of English teaching methods. In China, English teaching belongs to Teaching English as Foreign Language, which means there is no English language environment in Chinese Learners' life. Consequently, it is inevitable for the learners to adopt Chinese to assist their learning. Given the situation, it is worthwhile to research the application of translation in English teaching.

\section{Historical Development of Grammar Translation Method}

Translation has traditionally been applied to second language teaching, which first emerged as the form of Grammar Translation. The Grammar-Translation Method began in Prussia at the end of the eighteenth century with the publication of a French course-book and an English course-book for secondary school pupils, authored by Johann Valentin Meidinger in 1783 and Johann Christian Frick in 1793 respectively(Howatt 2004:152) ${ }^{[1]}$. While the method is applied, learners are first exposed to the grammatical rules and then practice translation by applying the rules with the medium of their mother tongue: "Each grammar point was exemplified with a set of sentences created ad hoc in the L2(second language) alongside their literal translation in the L1(first language). Vocabulary was learnt by memorizing bilingual lists of lexical items and phrases."(Sara 2014:5) ${ }^{[2]}$ As a result, the Grammar-Translation Method involves at least three factors: grammar rules, literal translation exercises and dependence on native language.

Although the Grammar Translation Method has been widely applied, it has been strongly condemned for its certain limitations. Duff(1989:5 ${ }^{[3]}$ summarizes what many teachers think of translation:

(1)It is text-bound and confined to only two skills-reading and writing; it is not a communicative activity because it involves no oral interaction. (2)It is not suitable for classroom work because the students must do the writing on their own; it is also time-consuming and wasteful. (3) It is associated with "different language", with literary or scientific texts and is not suited to the general needs of the second language learner. (4) Use of mother tongue is required in translation, and this is not desirable. (5)It is boring bother to do 
and to correct.

Stem(1999: $455-456)^{[4]}$ points out its main defects "lies in the overemphasis on the language as a mass of rules(and exceptions) and in the limitations of practice techniques which never emancipate the learner from the dominance of the first language." Richards and Rogers(2000:3) ${ }^{[5]}$ more specifically demonstrate its faults: "reading and writing are the major focus; little or no systematic attention is paid to speaking and listening". The emergence of structural linguistics and behaviorist language learning theory and the development in analysis of first language acquisition have accelerated the decline of Grammar Translation Method. Structural linguistics is "an approach to linguistics which stresses the importance of language as a system and which investigates the place that linguistic units as sounds, words, sentences have within this system"(Richards, et al, 2000:448). ${ }^{[6]}$ According to Behaviorism, learning is a habit-forming process through an interaction between stimulus and response and old habits will impede the acquisition of the new ones. Consequently, if there are great differences between the native language and the second language, then the native language, as a medium of teaching the second language, only leads to the negative transfer, which serves to obstruct the acquisition of the second language. When Grammar Translation Method fails to improve learners' oral proficiency, first language acquisition is resorted to. All those factors combined contribute to the removal of the native language from the language learning process, thus giving birth to the decline of Grammar Translation Method.

Recent years have witnessed the revival of Translation Method. Numerous scholars, such as Howatt(1984) ${ }^{[7]}, \operatorname{Duff}(1989)^{[3]}, \operatorname{Stern}(1991)^{[4]}$ and Baker(2004) $)^{[8]}$, have questioned the elimination of translation from the second language teaching. Baker argues that the current second language acquisition theories are doubtable, "especially in their denial of the inevitable wish of teachers and learners to attempt a conscious and systematic relation of the first language to the second language via translation"(Baker, 2004:119). ${ }^{[8]}$ On the other hand, "Ever since its emergence, Grammar Translation Method has encountered considerable challenges and heavy criticism from all sides. Despite that, translation method is always being improved. With the accumulation of plentiful experience, it, in the mid- $20^{\text {th }}$ century, made tremendous progress in both theory and practice, which evolves to be Modern Grammar Translation Method."(Zhang Jianzhong, 1986:10) ${ }^{[9]}$ Traditional Grammar Translation Method has been improved and perfected, and the modern translation method is formed with the following features:"1)Pronunciation education is intertwined with grammar and vocabulary instruction; 2)The cultivation of reading and translating is the focus with attention to listening, speaking and writing;3)Grammar dominates the instruction of reading so much so that students read and translate the texts under the guidance of grammar;4)The native language function as foundation and translation serves as a teaching method as well as a teaching goal."(Duan Wenzhi, $1997)^{[10]}$

\section{Necessity of Applying Translation in China's English Teaching}

English is regarded as a foreign language instead of a second language in China so that Chinese English learners lack the sufficient exposure to it, which the second language learners are entitled to. Chinese English learners have few chances to speak English in their real lives, except in their classrooms. Furthermore, class size is a little bigger so that class interactions are comparatively insufficient. The communicative method does not apply to the situation of China's English instruction for the lack of the language environment. Owing to the great imbalance of Chinese and English input, it is impossible to eliminate the influence of Chinese on the acquisition of English.

Besides, Chinese students are growing up under the impact of Chinese culture, which causes them to be accustomed to teacher-centered learning style. In class, the teachers are the authority and 
students play passive roles, which cannot be changed in a short time. The communicative teaching method does not apply to the Chinese students' learning style and habits. In addition, the English class time is so limited that teachers cannot afford to spend much time teaching English with English. Certain knowledge of the English language is easy to convey to Chinese English learners with translation, yet is hard to do so without it. For example, the word "velvet", if explained in English, is "soft material made from cotton, silk, or nylon, that has a thick layer of short cut threads on one side"(Yao Naiqiang, 2008) ${ }^{[11]}$. It is time-consuming and confusing. With the medium of Chinese, it is simple and easy to understand---“Tian' e rong”. And it is worth mentioning, the majority of English learners study English in order to pass certain tests, such as College Entrance Exam, Band 4 or 8, CET4 or 6, Professional Qualification Test, in which translation is an important part. In order to pass these exams, translation is an indispensable teaching content. As a result, it is necessary to adopt translation method in China's English teaching, given China's language environment.

Besides, Chinese English learners are doing translation unconsciously while learning English so it is unlikely to exclude the translation from English to Chinese during their learning process. Knowledge is something actively constructed by learners based on their existing cognitive structures (Yang Xianyu,2002) ${ }^{[12]}$. The English language is the knowledge whose acquisition depends on their knowledge of their Chinese knowledge. By translating English into Chinese, learners associates the new input with their previous knowledge to realize the transfer of their native language knowledge into the English language system. Since the translation is a subconscious, if not an unconscious process, attempting to remove the translation from English to Chinese is just attempting the impossible.

In addition, Chinese English educators have been influenced by the development of western language teaching theory. China has witnessed the prosperity and the decline of Translation Method. Although it is undeniable that the application of communicative language teaching method in China improves greatly the learners' oral English, yet it has caused many problems: the weakening of systematic grammar teaching has caused students' poor writing and many grammatical mistakes in speaking. And the so-called authentic language environment is not as authentic as expected for many conversations in course books are artificial. Therefore, more and more educators resort to translation again to bridge the students' grammatical loopholes, which lead to the revival of the translation method.

\section{Application of Translation in China's English Teaching}

Since it is essential to apply translation in China's English Teaching, it is worth discussing how to apply it.

First, given that Chinese is the dominant language environment and Chinese English learners tend to integrate their Chinese knowledge into their English knowledge, it is a necessity to add the teaching materials of comparisons and contrasts between Chinese and English. Since there are great differences as well as certain similarities between Chinese and English, there can be positive and negative transfer when students try to transfer their constructed Chinese knowledge to acquire the knowledge of English. Positive transfer occurs if there exist similarities whereas negative transfer if differences. In order to maximize the positive transfer and minimize the negative transfer, it is indispensable to teach students the differences and similarities between English and Chinese. For example, there are no articles in Chinese so Chinese English learners often speak or write these sentences: I am student; I like apple. Through contrasts, they will know articles are indispensable parts in these situations, thus negative transfer can be avoided. 
Secondly, although teachers are encouraged to teach English in English, translation should be allowed whenever necessary. When teachers teach English grammar, it is hard for them to explain them clearly in English, even harder for students to understand for there are many difficult terms. Even if the teacher is capable of teaching grammar in English, it is not worth doing that for he or she has to spend much time teaching students the terms to remove their comprehension difficulties caused by them, which are of little value to the students in the long term. If teachers resort to Chinese, it can save both them and their students much trouble and time. For example, when the present tense is taught, the teacher explains the situations in which the tense is suitable to use in English. His or her explanation is that the tense should be applied when the action happens regularly, habitually, at present and when the fact narrated is the truth. This English explanation is very clear in itself, yet it is hard for students to comprehend on account of their poor English proficiency. If Chinese is adopted, the language obstacle to the understanding will be eliminated and the students can easily master the grammar. Besides when teachers teach English words, especially some abstract ones, and their English explanations confuse their students, it is necessary for teachers to translate their explanation into Chinese so that their students can understand what the words mean immediately. On the other hand, students should be permitted to use Chinese when they fail to express themselves in English. When students encounter barriers in their classroom English learning, it is instinctive for them to turn to Chinese. In these situations, Chinese should be allowed for it assists students conquer their learning difficulties and facilitate their further communication in English, thus increase students' practice in English. For example, when students are required to talk about their ideals and a student does not know how to express his ideal to be an astronaut in English, he can be allowed to use the Chinese "Yu Hang Yuan" in his English presentation so that he can continue his speech in English rather than stop speaking English for the failure of one English word. Moreover, when students are permitted to turn to Chinese whenever English words fail them, they will have the sense of confidence and security, which will be of great aid to their learning of English.

Thirdly, translation should be adopted when teachers check the language mastery of their students. When teachers plan to assess whether their students have understood the texts, they can require their students to translate the text from English to Chinese sentence by sentence. When teachers want to check whether their students have mastered the usage of the word, they can ask their students to translate several sentences with the word involved. When these activities are carried out, students' attention has been attracted. Besides, in such case, students actively participate in the learning instead of just sitting there listening, which will greatly increase their initiative in English learning.

Last but not least, translation can be used to improve students' writing. When teachers plan to ask students to write an essay about a topic, they can first prepare the translation exercise of some sentence on the topic, as preparation for the essay draft. Then the teachers demonstrate to the students how to write an essay by combining these sentences with certain connectives. How to apply translation properly is of great value in promoting China's English Teaching.

\section{Conclusion}

Translation, as a way of teaching English, should not be abandoned given the situation of Chinese English instruction. It has withstood the test of time and experienced the original prosperity, the mid-term decline and the recent revival. During the process, the translation method has developed and improved by continuously overcoming its own prior defects. The poor language environment of China deprived English learners of sufficient exposure to it, so it is necessary to 
allow teachers and students to turn to Chinese whenever they feel necessary. It is suggested in the essay that teachers can add the teaching materials concerning the comparative analysis of Chinese and English, check students' mastery of the language and train their writing by appropriate arrangement of certain translation exercises. It is feasible to apply translation to the instruction of English in China as long as it helps the learners master the language with a sense of confidence and security. More research is necessary to focus on the specific application of the translation method.

\section{Reference}

[1] Howatt, A.P.R., Widdowson H.G., A History of English Language Teaching, 2nd edition, Oxford University Press, Oxford, 2004.

[2] Sara Laviosa, Translation and Language Education: Pedagogic Approaches Explored, Routledge, Oxford and New York, 2014.

[3] Duff A., Translation, Oxford University Press Education Press, Oxford, 1989.

[4] Stern H.H., Fundamental Concepts of Language Teaching, Foreign Language Education Press, Shanghai, 1999.

[5] Richards J.C., Rodgers, T.S., Approaches and Methods in Language Teaching, Foreign Language Teaching and Research Press, Beijing, 2000.

[6] Richards J.C., et al., Longman Dictionary of Language Teaching and Applied Linguistics, Foreign Language Teaching and Research Press, Beijing, 2000.

[7] Howatt A.P.R., A History of English Language Teaching, Oxford University Press, Oxford, 1984.

[8] Baker Mona, Routledge Encyclopedia of Translation Studies, Foreign Language Education Press, Shanghai, 2004.

[9] Zhang Jianzhong, Foreign Language Education Psychology, Anhui Education Press, Hefei, 1986.

[10] Duan Wenzhi, Comparison Between Several Foreign Language Teaching Methods, Dandong Normal School Journal, 02(1997).

[11] Yao Naiqiang, et al., Collins Learner's English Chinese Dictionary, Commercial Press, Shanghai, 2008.

[12] Yang Xianyu, Translation Theory and Teaching Practice, Huangzhong Science and Technology University Press, Wuhan, 2002. 